\title{
A Coupled Homogenisation-Damage Model for Masonry Cracking
}

\author{
A. ZUCCHINI $^{1}$ \\ ENEA, FIS.MET, C.R.E. “E.Clementel”, v. Don Fiammelli, 2, I - 40129 Bologna, Italy.
}

P.B. LOURENÇO *

University of Minho, Department of Civil Engineering, Azurém, P - 4800-058 Guimarães, Portugal

${ }^{1}$ E-mail: zucchini@bologna.enea.it,Ph: +39 0516098256, Fax: +39 0516098062

*Corresponding author. E-mail: pbl@ civil.uminho.pt, Ph: + 351253510200 , Fax: + 351253510217 


\begin{abstract}
Cracking is responsible for the vast majority of masonry non-linear behaviour, due to the low tensile strength of the material. Masonry features orthotropic behaviour with material axes normal and parallel to the bed joints, being the response straightforward for tension normal to the bed joints and rather complex for tension parallel to the bed joints. This paper addresses the formulation and implementation of coupling between a micro-mechanical homogenisation model and an isotropic damage model for the masonry components. The non-linear homogenisation formulation requires an improved internal deformation mode of the masonry basic cell, with respect to previous works. Finally, the model is validated with a comparison with numerical results available in the literature, using interface modelling.
\end{abstract}

\title{
KEYWORDS
}

Masonry, Homogenisation, Macro-modelling, Damage mechanics, Cracking 


\section{Introduction}

Masonry is a heterogeneous material that consists of units and joints. Units are such as bricks, blocks, ashlars, adobes, irregular stones and others. Mortar can be clay, bitumen, chalk, lime/cement based mortar, glue or other. The huge number of possible combinations generated by the geometry, nature and arrangement of units as well as the characteristics of mortars raises doubts about the accuracy of the term "masonry". Still, much information can be gained from the study of regular masonry structures, in which a periodic repetition of the microstructure occurs due to a constant arrangement of the units (or constant bond).

The difficulties in performing advanced testing of this type of structures are quite large due to the innumerable variations of masonry, the large scatter of in situ material properties and the impossibility of reproducing it all in a specimen. Therefore, most of the advanced experimental research carried out in the last decades concentrated in brick / block masonry and its relevance for design. Accurate modelling requires a comprehensive experimental description of the material, which seems mostly available at the present state of knowledge, see e.g. CUR (1997) and Lourenço (1998) for a review.

The present paper focuses on a particular possibility of non-linear analysis of masonry structures, making use of homogenisation techniques. Cracking is responsible for the vast majority of masonry non-linear behaviour, due to the low tensile strength of the material. The problem of simulating the composite behaviour of masonry under tension must be addressed along the masonry material axes, namely the direction defined by the parallel and the normal to the bed joints. Loading normal to the bed 
joints is usually simple to describe as the cracks localise in the unit-mortar interface. Loading parallel to the bed joints is difficult to describe and simulate because the response results from a complex interaction of the interface and unit, both in the case of a stepped crack through head and bed joints, and in the case of a straight crack through unit and head joints. Therefore, in the present paper, a homogenisation formulation based on the observation of the deformation of masonry, Zucchini and Lourenço (2002) is extended with a damage model and is validated for the case of masonry under uniaxial tension parallel to the bed joints. With this development, the obtained model is able to reproduce the behaviour of most masonry structures, in which non-linearities are due to cracking.

\section{Modelling Masonry Structures}

In general, the approach towards the numerical representation of masonry can focus on the micro-modelling of the individual components, viz. unit (brick, block, etc.) and mortar, or the macro-modelling of masonry as a composite, Rots (1991). Depending on the level of accuracy and the simplicity desired, it is possible to use the following modelling strategies, see Fig. 1:

- Detailed micro-modelling - units and mortar in the joints are represented by continuum elements whereas the unit-mortar interface is represented by discontinuum elements;

- Simplified micro-modelling - expanded units are represented by continuum elements whereas the behaviour of the mortar joints and unit-mortar interface is lumped in discontinuum elements; 
- Macro-modelling - units, mortar and unit-mortar interface are smeared out in a homogeneous continuum.

In the first approach, Young's modulus, Poisson's ratio and, optionally, inelastic properties of both unit and mortar are taken into account. The interface represents a potential crack/slip plane with initial dummy stiffness to avoid interpenetration of the continuum. This enables the combined action of unit, mortar and interface to be studied under a magnifying glass. In the second approach, each joint, consisting of mortar and the two unitmortar interfaces, is lumped into an average interface while the units are expanded in order to keep the geometry unchanged. Masonry is thus considered as a set of elastic blocks bonded by potential fracture/slip lines at the joints. Accuracy is lost since Poisson's effect of the mortar is not included. The third approach does not make a distinction between individual units and joints but treats masonry as a homogeneous anisotropic continuum. One modelling strategy cannot be preferred over the other because different application fields exist for micro- and macro-models. In particular, micro-modelling studies are necessary to give a better understanding about the local behaviour of masonry structures.

It is noted that different levels of sophistication can also be adopted to create structural models, namely structural component models or continuum structural models (macro-modelling approaches) and discontinuum structural models (a micro-modelling approach). Difficulties of conceiving and implementing macro-models for the analysis of masonry structures arise especially due to the intrinsic complexity of formulating anisotropic inelastic behaviour. Only a reduced number of authors tried to develop specific models for the analysis of masonry structures, e.g. Dhanasekar et al. 
(1985), Lourenço et al. (1998), Berto et al. (2002), using different inelastic criteria for tension and compression. Therefore, the homogenisation techniques shown in Fig. 2, which permit to establish constitutive relations in terms of averaged stresses and strains from the geometry and constitutive relations of the individual components, can represent a step forward in masonry modelling, mostly because of the possibility to use standard material models and software codes for isotropic materials.

The most popular homogenisation approach replaces the complex geometry of the basic cell by a simplified geometry so that a close-form solution of the homogenisation problem is possible, e.g. Pande et al. (1989) and Maier et al. (1991). The homogenisation has generally been performed in two steps, head (or vertical) and bed (or horizontal) joints being introduced successively. The use of two separate homogenisation steps does not explicitly account for the regular offset of vertical mortar joints belonging to two consecutive layered unit courses, which results in significant errors in the case of non-linear analysis.

To overcome these issues, micromechanical homogenisation approaches that consider additional internal deformation mechanisms have been derived, independently, by van der Pluijm (1999), Lopez et al. (1999) and Zucchini and Lourenço (2002).

\section{Formulation of the micro-mechanical model}

\subsection{General}

As shown in Zucchini and Lourenço (2002), the mechanical properties of an orthotropic material equivalent to the basic masonry cell can be derived from a suitable micromechanical model with the introduction of 
appropriate deformation mechanisms, which take into account the staggered alignment of the units in a masonry wall. The unknown internal stresses and strains can be found from equilibrium equations at the interfaces between the basic cell components, with a few ingenious assumptions on the cross joint behaviour and on the kinematics of the basic cell deformation. The equivalent properties of the homogenised material are then easily derived by forcing the macro-deformation of the model and of the material to be the same, meaning that both systems must contain the same strain energy. Fig. 3 shows the geometry considered in the present paper for the basic masonry cell and its components.

\subsection{Equilibrium equations}

As referred before, this paper addresses specifically the problem of a basic masonry cell under tensile loading parallel to the bed joint. When the basic cell is loaded only with normal stresses, the micromechanical model of Zucchini and Lourenço (2002) assumes that all shear stresses and strains inside the basic cell can be neglected, except the in-plane shear stress and strain $\left(\sigma_{x y}\right.$ and $\left.\varepsilon_{x y}\right)$ in the bed joint and in the unit. The non-zero stresses and strains have been assumed to be constant in each basic cell component, with the exception of the normal stress $\sigma_{x x}$ in the unit, which is a linear function of $x$ and accounts for the effect of the shear $\sigma_{x y}$ in the bed joint, and with the exception of the shear stress $\sigma_{x y}$ in the unit, which is linear in $y$. For the undamaged (elastic) basic cell, the following linear system of 20 equations and 24 variables (the internal and boundary stresses and strains) has been obtained in the case of tension parallel to the bed joint, Zucchini and Lourenço (2002): 


$$
\begin{array}{ll}
\sigma_{x x}^{2}=\bar{\sigma}_{x x}^{b}-\sigma_{x y}^{1} \frac{l-t}{2 h} & \text { Interface brick-head joint } \\
\sigma_{y y}^{b}=\sigma_{y y}^{1} & \text { Interface brick-bed joint }
\end{array}
$$

$$
h \sigma_{x x}^{2}+2 t \sigma_{x x}^{3}+h\left(\bar{\sigma}_{x x}^{b}+\sigma_{x y}^{1} \frac{l-t}{2 h}\right)=2(h+t) \sigma_{x x}^{0} \quad \text { Right boundary }
$$

$$
l \sigma_{y y}^{b}+t \sigma_{y y}^{2}=0
$$

Upper boundary

$$
2 t h \sigma_{z z}^{2}+2(l-t) t \sigma_{z z}^{1}+2 l h \sigma_{z z}^{b}+4 t^{2} \sigma_{z z}^{3}=0
$$

Front boundary

$2 t \varepsilon_{y y}^{1}+h \varepsilon_{y y}^{b}=h \varepsilon_{y y}^{2}+2 t \varepsilon_{y y}^{3}$

Upper boundary

$t \varepsilon_{x x}^{2}+l \bar{\varepsilon}_{x x}^{b}=2 t \varepsilon_{x x}^{3}+(l-t) \varepsilon_{x x}^{1}$

Right boundary

$\varepsilon_{z z}^{b}=\varepsilon_{z z}^{1}$

Front boundary

$\varepsilon_{z z}^{b}=\varepsilon_{z z}^{2}$

Front boundary

$\varepsilon_{x x}^{k}=\frac{1}{E_{k}}\left[\sigma_{x x}^{k}-v_{k}\left(\sigma_{y y}^{k}+\sigma_{z z}^{k}\right)\right]$

$\varepsilon_{y y}^{k}=\frac{1}{E_{k}}\left[\sigma_{y y}^{k}-v_{k}\left(\sigma_{x x}^{k}+\sigma_{z z}^{k}\right)\right]$

$\mathrm{k}=\mathrm{b}, 1,2$

$\varepsilon_{z z}^{k}=\frac{1}{E_{k}}\left[\sigma_{z z}^{k}-v_{k}\left(\sigma_{x x}^{k}+\sigma_{y y}^{k}\right)\right]$

$$
\varepsilon_{x y}^{1} \cong \frac{\varepsilon_{x x}^{2}-\bar{\varepsilon}_{x x}^{b}}{4}
$$

$\sigma_{x y}^{1}=2 G_{1} \varepsilon_{x y}^{1}$

where, as shown in Fig. $4, l$ is half of the unit length, $h$ is half of the unit height and $t$ is half of the bed joint width. Here also, $E$ is the Young modulus, $G$ is the shear modulus, $v$ is the Poisson coefficient, $\varepsilon$ is the strain component and $\sigma$ is the stress component. Unit, bed joint, head joint and cross joint variables are indicated throughout this paper, respectively by the superscripts $b, 1,2$ and 3, as shown in Fig. 4. $\bar{\sigma}_{x x}^{b}$ and $\bar{\varepsilon}_{x x}^{b}$ are the mean value of the normal stress $\sigma_{x x}$ and of the normal strain $\varepsilon_{x x}$ in the unit, 
respectively. $\sigma_{x x}^{0}$ is the uniform normal (macro) stress on the faces of the homogenised basic cell perpendicular to the bed joint.

In Eqs.(1)-(12) the four unknown stresses and strains in the cross joint can be eliminated by means of the following assumptions:

$$
\begin{aligned}
\varepsilon_{y y}^{3}=\frac{E_{2}}{E_{3}} \varepsilon_{y y}^{2} & , & \varepsilon_{x x}^{3}=\frac{E_{1}}{E_{3}} \varepsilon_{x x}^{1} \\
\sigma_{z z}^{3}=\frac{E_{3}}{E_{1}} \sigma_{z z}^{1} & , & \sigma_{x x}^{3}=\sigma_{x x}^{1}
\end{aligned}
$$

The unknowns, left in the equation system of the model, are then the six normal stresses and strains of the three components (unit, head joint and bed joint) and the shear stress and shear strain in the bed joint, amounting to a total of 20 unknowns.

The last two equations of the system (Eqs.(11)-(12)) have been derived introducing the shear deformation of the bed joint: the elastic mismatch between the normal $x$ strains in the unit and in the joints is responsible for the shear in the bed joint because of the staggered alignment of the units in a masonry wall, see Fig. 5 and Zucchini and Lourenço (2002). It is noted that the shear deformation of the unit was neglected in the derivation of Eq.(11).

\subsection{Improved unit model}

Application of the model described above to non-linear analysis has shown that, for thin mortar joints, e.g. as in the case of Lourenço et al. (1999), where the ratio between the thickness of the joint and the height of the unit, $t / h$, is as low as 0.005 , the results deviate from the solution obtained by a full micro-modelling finite element analysis. In this case, it has been found that neglecting the shear deformation of the unit, as done by the original 
model, leads to an overestimation of the masonry stiffness. An improved shear mechanism of the basic cell, in the case of normal stress parallel to the bed joint, has therefore been developed, using a more refined model for the shear deformation of the unit.

The stress problem of a single unit subjected to the loading conditions shown in Fig. 6 are first addressed. Such assumed loading conditions are of interest for tensile behaviour of the basic cell parallel to the bed joint. The next step is to find an approximation of the stress-strain fields in the unit, capable of reproducing the following boundary conditions:

$$
\begin{aligned}
& \left(\int_{0}^{l} \sigma_{x y} d x\right)_{y=-h}=l \sigma_{x y}^{1} \\
& \left(\int_{0}^{h} \sigma_{x x} d y\right)_{x=0}=h \sigma_{x x}^{b 1} \\
& \left(u_{x}\right)_{x=l}=\text { const. }
\end{aligned}
$$

$$
\left(\int_{0}^{l} \sigma_{x y} d x\right)_{y=0}=0
$$

$$
\left(\int_{0}^{h} \sigma_{x x} d y\right)_{x=l}=h \sigma_{x x}^{b 2}
$$

Here, $u$ represents the horizontal displacements in the unit, and $b 1, b 2$ represent the left and right edges of the unit. Eq.(16) reflects directly the symmetry of the cell problem, while Eq.(19) is justified also by the symmetry of the cell problem, see Fig. 3 . The shear stress at the boundary is known only by its resultant $F_{x y}=l \sigma_{x y}^{1}$. Because, in the basic cell, the shear stress in the bed joint $\sigma_{x y}^{1}$ and the normal stress $\sigma_{x x}$ are assumed respectively constant in $x$ and in $y$, equilibrium at the unit interfaces is imposed only as a global (average) condition, cf. Eq.(15) and Eq.(17)-(18), and not locally. Eq.(15) and Eq.(17)-(18) define the average stresses on the sides of the unit due to the interaction of the unit with the boundary. These boundary stresses are used to formulate the internal equilibrium of the cell, see Section 3.2. 
For simplicity, a bilinear form for the shear stress will be assumed, as

$$
\sigma_{x y}=(a+b x)(c+d y)
$$

and therefore

$$
\int_{0}^{l} \sigma_{x y} d x=l\left(a+b \frac{l}{2}\right)(c+d y)
$$

which, after introducing Eq.(16), yields

$$
c=0 \text {. }
$$

The last result is due to the fact that $\left(a+b \frac{l}{2}\right)$ cannot be equal to zero, otherwise Eq.(15) would not be satisfied. In a similar way, it is possible to obtain from Eq.(15)

$$
d=-\frac{\sigma_{x y}^{1}}{h\left(a+b \frac{l}{2}\right)} \text {. }
$$

In this new deformation mode, the gradient $\frac{\partial u_{y}}{\partial x}$ will be neglected. Thus, integration of the continuum mechanics relation

$$
\varepsilon_{x y}=\frac{\sigma_{x y}}{2 G}=\frac{1}{2}\left(\frac{\partial u_{x}}{\partial y}+\frac{\partial u_{y}}{\partial x}\right) \cong \frac{1}{2}\left(\frac{\partial u_{x}}{\partial y}\right),
$$

with the introduction of Eq. (20) and Eq.(22), leads to

$$
u_{x}=\frac{d}{G}(a+b x) \frac{y^{2}}{2}+f(x)
$$

Here, $f(x)$ represents any function independent of $y$. The displacement in $x$, at $x=l$, is independent from $y$, as indicated in Eq.(19), therefore the following relations must hold:

$$
a=-b l \quad \text { and } \quad f(l)=u_{0} .
$$

Introducing Eq.(26.1) in Eq.(23), it is possible to obtain 


$$
d=\frac{2 \sigma_{x y}^{1}}{h b l}
$$

and finally, replacing $a$ and $d$ in Eq.(25), the horizontal displacement $u_{x}$ reads

$$
u_{x}=-\frac{\sigma_{x y}^{1}}{G}\left(1-\frac{x}{l}\right) \frac{y^{2}}{h}+f(x)
$$

With this result and Eq.(24), the shear stress $\sigma_{x y}$ reads

$$
\sigma_{x y}=-2 \sigma_{x y}^{1}\left(1-\frac{x}{l}\right) \frac{y}{h}
$$

Eq.(24) is clearly an approximation which characterizes the new deformation mode of the unit in the basic cell. Due to the impossibility of obtaining an explicit solution for the boundary value problem, the adequacy of the adopted assumptions and of the adopted mechanism can only be assessed, a posteriori, from a comparison with a micro-modelling finite element solution. The problem of the single unit in Fig. 6 has been analysed by FEM for a length to height ratio of the unit $l / h=1 \div 3$ and a thickness ratio of the unit equal to six, as in the masonry geometry of Lourenço et al.(1999). Fig. 7 shows the relative error on

$$
\varepsilon_{x y}^{*}=\frac{\left(u_{x}\right)_{x=0, y=h}-\left(u_{x}\right)_{x=0, y=0}}{2 h}
$$

introduced by the unit model $\left(\varepsilon_{x y}^{*}=\frac{\sigma_{x y}^{1}}{2 G}\right)$, compared to the FEM results. In such a way, it is observed that the displacement field calculated from Eq.(28) is in good agreement with the finite element results, with an error less than $5 \%$ for any ratio $l / h>1$, even if some deformation in $y$ does occur. 
The normal stress in $x$ can be found, from continuum mechanics, as

$$
\frac{\partial \sigma_{x}}{\partial x}+\frac{\partial \sigma_{x y}}{\partial y}=0
$$

which can be easily integrated. This operation results in

$$
\sigma_{x x}=\frac{2 \sigma_{x y}^{1}}{h} x\left(1-\frac{x}{2 l}\right)+g(y)
$$

where $g(y)$ is any function independent of $x$. Then, by means of the boundary conditions given by Eq.(17)-(18), it is possible to obtain :

$$
\int_{0}^{h} g(y) d y=h \sigma_{x x}^{b 1}
$$

and

$$
l \sigma_{x y}^{1}+h \sigma_{x x}^{b 1}=h \sigma_{x x}^{b 2}
$$

which shows that the stress field in the unit satisfies the equilibrium in the $x$ direction, as required.

The original deformation mode of the basic cell, under tension parallel to the bed joint, can now be improved by taking into account the shear deformation in the unit, given by Eq.(28). The modified mechanism is shown in Fig. 8, cf. with Fig. 5, where $\Delta x_{2}$ is the average displacement at the unit-head joint interface. This average displacement, by means of Eq.(28), reads:

$$
\Delta x_{2}=\left(\bar{u}_{x}\right)_{x=0}=\left(\frac{\int_{0}^{h} u_{x} d y}{\int_{0}^{h} d y}\right)_{x=0}=-\frac{h \sigma_{x y}^{1}}{3 G_{b}}+f(0) .
$$

From Fig. 8, it is straightforward to observe that the following relations hold:

$$
\Delta x_{1}=\Delta x_{2}-\Delta x_{b}-\Delta
$$




$$
\Delta x_{2}=t \varepsilon_{x x}^{2} \quad, \quad \Delta x_{b}=t \varepsilon_{x x}^{b 2}
$$

$$
\Delta=\left(\bar{u}_{x}\right)_{x=0}-\left(u_{x}\right)_{x=0, y=-h}
$$

where $\varepsilon_{x x}^{b 2}$ indicates the normal strain on the right side (i.e. straight centre line) of the unit, see Fig. 6. Then, Eq.(38), by means of Eq.(28) and Eq.(35), yields :

$$
\Delta=\frac{2 h \sigma_{x y}^{1}}{3 G_{b}}
$$

Finally, the shear deformation of the bed joint, according to the mechanism shown in Fig. 8 and Eq.(36), can now be derived as:

$$
\varepsilon_{x y}^{1}=\frac{1}{2} \frac{\Delta x_{1}}{2 t} \cong \frac{\varepsilon_{x x}^{2}-\bar{\varepsilon}_{x x}^{b}}{4}-\frac{h}{6 G_{b}} \sigma_{x y}^{1}
$$

where $\varepsilon_{x x}^{b 2}$ has been approximated by the average strain in the unit $\bar{\varepsilon}_{x x}^{b}$.

This last equation replaces now Eq.(11) in the original system of equations of the micromechanical model. The only difference is due to the term $\Delta$, given by Eq.(39), which reduces the deformation of the bed joint, producing a lower overall stiffness of the basic cell. This effect can be significant for high ratios $h / t$ of the cell and for high stress levels in the bed joint, e. g. when the stiffness of the head joint is highly degraded and the bed joint still possesses considerable stiffness, as it should be expected in the case of non-linear analysis.

\section{Extension of the formulation to accommodate inelastic behaviour}

To simulate the inelastic deformation of masonry in tension, the micromechanical model, detailed in the previous section, has to be coupled with a non-linear constitutive model. Here, damage mechanics has been 
adopted to represent the inelastic behaviour of the cell basic components. Because the three-dimensional micromechanical model attempts to simulate the discrete internal structure of the basic cell, and implicitly the global anisotropic behaviour, the damage in each homogeneous isotropic component (joint or unit) must be taken into account. The advantage of this approach is that, for each component, an isotropic scalar damage model, with a single parameter, can be utilised, with obvious gains in simplicity and easiness of implementation.

\subsection{Formulation of the isotropic damage model}

Continuum damage mechanics allows an effective simulation of the progressive deterioration of the mechanical properties, under increasing loading, in quasi-brittle materials such as concrete, rocks and masonry. The dissipative effects of micro-cracking in the material are taken into account by means of internal state variables, which affect the material strength and stiffness. In this work an isotropic damage model with a single damage variable in tension for each component of the basic cell has been adopted, see e.g. Mazars(1986), Mazars and Pijaudier-Cabot (1989), and Scotta et al. (2001). The proposed model, for each component of the basic cell, consists of:

\section{a) Scalar damage model}

The damaged $\sigma_{d}$ and undamaged $\boldsymbol{\sigma}$ (or effective) stress tensors are correlated, according to continuum damage mechanics, by the relation:

$$
\boldsymbol{\sigma}_{d}=(1-d) \mathbf{D} \boldsymbol{\varepsilon}=(1-d) \boldsymbol{\sigma}
$$

where $d$ is a scalar value, ranging from 0 to 1 and representing the local damage parameter, $\mathbf{D}$ is the elastic stiffness matrix and $\boldsymbol{\varepsilon}$ is the strain tensor. b) Limit damage surface 
The limit damage surface is given by

$$
\bar{\sigma}=\sigma_{t}
$$

where $\bar{\sigma}$ is the equivalent effective stress, a scalar function of the undamaged stress, and $\sigma_{t}$ is the tensile strength of the given cell component.

c) Equivalent effective stress

The equivalent effective stress is here defined as the maximum principal tensile stress $\sigma_{p}$ :

$$
\bar{\sigma}=\sigma_{p}
$$

(Rankine criteria)

d) Damage evolution law

In this work, the explicit function, proposed by Oliver et al. (1990) for concrete-like materials, is adopted:

$$
d=1-\frac{\sigma_{t}}{\bar{\sigma}} e^{A\left(1-\frac{\bar{\sigma}}{\sigma_{t}}\right)} \quad \sigma_{t} \leq \bar{\sigma} \leq \infty
$$

where $A$ is a parameter chosen to reproduce the observed experimental behaviour, and the irreversibility of the damage process is accounted for by updating the damage coefficient only for increasing values.

e) Correlation with fracture parameters

For mode I fracture (head joint) it is shown in Scotta et al. (2001) that the damage model parameter $A_{t}$ can be related to the specific fracture energy in uniaxial tension $g^{I}\left(\mathrm{~N} / \mathrm{m}^{2}\right)$ of the material by

$$
g^{I}=\frac{\sigma_{t}^{2}}{E}\left(\frac{1}{2}+\frac{1}{A_{t}}\right)
$$


where $E$ is the Young modulus. Introducing the characteristic internal length of fracture $l_{t}=\frac{G^{I}}{g^{I}}$, where $G^{I}$ is the mode I fracture energy $\left(\mathrm{N} / \mathrm{m}^{2} . \mathrm{m}\right)$, it is straightforward to obtain:

$$
A_{t}=\left(\frac{G^{I} E}{l_{t} \sigma_{t}^{2}}-\frac{1}{2}\right)^{-1}
$$

Similarly, an explicit relation for the fracture energy in shear can be found.

The uniaxial damage model for mode II fracture of the bed joint becomes:

$$
\begin{aligned}
& \tau=2 G \varepsilon_{x y} \\
& d=1-\frac{\sigma_{s}}{\tau} e^{A_{s}\left(1-\frac{\tau}{\sigma_{s}}\right)} \\
& \tau=(1-d) \tau
\end{aligned}
$$

By integration of the deformation energy on the full strain path, it is possible to obtain

$$
g^{I I}=\frac{\sigma_{s}^{2}}{G}\left(\frac{1}{2}+\frac{1}{A_{s}}\right)
$$

which yields a damage model parameter in shear (bed joint) $A_{s}$ equal to

$$
A_{s}=\left(\frac{G^{I I} G}{l_{s} \sigma_{s}^{2}}-\frac{1}{2}\right)^{-1}
$$

where $G$ is the shear modulus, $G^{I I}$ is the fracture energy in mode II, $\sigma_{s}$ is the shear strength and $l_{s}=\frac{G^{I I}}{g^{I I}}$.

\section{2. "Damaged" equilibrium equations}

Under increasing loading, the elastic micromechanical model of the cell has to be modified to take into account the material degradation of the cell and the consequent reduction of the load carrying capacity of each component. 
A single damage coefficient model has been assumed for each joint and the unit. The strain equations are unaffected by the presence of damage in the cell, while the stress equilibrium of damaged stresses at the interfaces can now be rewritten in terms of the undamaged stresses by means of Eq.(41). The equilibrium of the unit, Eq.(34), becomes

$$
\frac{(l-t)}{h} r^{1} \sigma_{x y}^{1}+r^{b} \sigma_{x}^{b 1}=r^{b} \sigma_{x}^{b 2}
$$

where it is assumed that the shear stress acts only on the bed-unit interface $(l-t)$ and the notation $r^{i}=\left(1-d^{i}\right)$ is introduced, with $i=1,2$ or $b$, respectively head joint, bed joint or unit.

If $\sigma_{x x}^{b}$ is linear in $x$, its mean value is given by

$$
\bar{\sigma}_{x x}^{b}=\frac{\sigma_{x x}^{b 1}+\sigma_{x x}^{b 2}}{2}
$$

and it is possible to obtain

$$
r^{b} \sigma_{x}^{b 2}=r^{b} \bar{\sigma}_{x}^{b}+\frac{(l-t)}{2 h} r^{1} \sigma_{x y}^{1}
$$

The formulation of the improved unit model, derived in Section 3, can still be applied to a damaged basic cell with the given boundary conditions. Thus, manipulation of Eqs.(15)-(18), referred to damaged stresses, results in, cf. Eqs.(29),(39):

$$
\begin{aligned}
& \sigma_{x y}=2\left(1-\frac{x}{l}\right)\left(1-\frac{y}{h}\right) \frac{r^{1}}{r^{b}} \sigma_{x y}^{1} \\
& \Delta=\frac{2 h}{3 G_{b}} \frac{r^{1}}{r^{b}} \sigma_{x y}^{1}
\end{aligned}
$$

Finally, the system of Eqs.(1)-(12) can be recast as

$$
r^{2} \sigma_{x x}^{2}=r^{b} \bar{\sigma}_{x x}^{b}-\frac{l-t}{2 h} r^{1} \sigma_{x y}^{1} \quad \text { Interface brick-head joint }
$$




$$
\begin{array}{lr}
r^{b} \sigma_{y y}^{b}=r^{1} \sigma_{y y}^{1} & \text { Interface brick-bed joint } \\
h r^{2} \sigma_{x x}^{2}+2 t r^{3} \sigma_{x x}^{3}+h\left(r^{b} \bar{\sigma}_{x x}^{b}+\frac{l-t}{2 h} r^{1} \sigma_{x y}^{1}\right)=2(h+t) \sigma_{x x}^{0}
\end{array}
$$

Right boundary

$$
\begin{array}{lr}
l r^{b} \sigma_{y y}^{b}+t r^{2} \sigma_{y y}^{2}=0 & \text { Upper boundary } \\
2 t h r^{2} \sigma_{z z}^{2}+2(l-t) t r^{1} \sigma_{z z}^{1}+2 l h r^{b} \sigma_{z z}^{b}+4 t^{2} r^{3} \sigma_{z z}^{3}=0
\end{array}
$$

Front boundary

$$
2 t \varepsilon_{y y}^{1}+h \varepsilon_{y y}^{b}=h \varepsilon_{y y}^{2}+2 t \varepsilon_{y y}^{3} \quad \text { Upper boundary }
$$

$$
t \varepsilon_{x x}^{2}+l \bar{\varepsilon}_{x x}^{b}=2 t \varepsilon_{x x}^{3}+(l-t) \varepsilon_{x x}^{1} \quad \text { Right boundary }
$$

$$
\varepsilon_{z z}^{b}=\varepsilon_{z z}^{1}
$$

Front boundary

$$
\varepsilon_{x x}^{k}=\frac{1}{E_{k}}\left[\sigma_{x x}^{k}-v_{k}\left(\sigma_{y y}^{k}+\sigma_{z z}^{k}\right)\right]
$$

$$
\varepsilon_{y y}^{k}=\frac{1}{E_{k}}\left[\sigma_{y y}^{k}-v_{k}\left(\sigma_{x x}^{k}+\sigma_{z z}^{k}\right)\right] \quad \mathrm{k}=\mathrm{b}, 1,2
$$$$
\varepsilon_{z z}^{k}=\frac{1}{E_{k}}\left[\sigma_{z z}^{k}-v_{k}\left(\sigma_{x x}^{k}+\sigma_{y y}^{k}\right)\right]
$$

$$
\varepsilon_{x y}^{1}=\frac{\varepsilon_{x x}^{2}-\bar{\varepsilon}_{x x}^{b}}{4}-\frac{h}{6 G_{b}} \frac{r^{1}}{r^{b}} \sigma_{x y}^{1}
$$

Eqs.(55) and (57) have been obtained by means of Eq.(52), while the shear strain equation, Eq.(65), is the equivalent of Eq.(40), when Eq.(54) is taken into account.

In the damaged cell model the different joints have the same Young modulus and differ only for the damage coefficient. The four unknown stresses and strains in the cross joint can be eliminated, in the system of Eqs.(55)-(66), by means of the following relations, cf. Eqs.(13)-(14), 


$$
\begin{array}{ll}
\varepsilon_{y y}^{3}=\frac{r_{2}}{r_{3}} \varepsilon_{y y}^{2} & , \quad \varepsilon_{x x}^{3}=\frac{r_{1}}{r_{3}} \varepsilon_{x x}^{1} \\
\sigma_{z z}^{3}=\sigma_{z z}^{1} & , \sigma_{x x}^{3}=\frac{r^{1}}{r^{3}} \sigma_{x x}^{1}
\end{array}
$$

These equations assume that the cross joint behaves as a spring connected in series with the bed joint in the $x$-direction, connected in series with the head joint in the $y$-direction and connected in parallel with the bed joint in the $z$ direction. Eq.(68.2) represents the equilibrium at the cross-bed joint interface. At last, in order to reduce the number of unknowns to twenty, as the number of equations in the above system, it is still necessary to define the damage in the cross joint. The stress-strain state in the cross joint does not play a major role in the problem, because of its small volume ratio, so the adopted approximation is the average of the damage in the head and bed joint, given by

$$
r^{3}=\frac{r^{1}+r^{2}}{2}
$$

The average shear stresses on the four sides of the unit can be calculated from the shear stress in the bed joint by means of Eq.(53):

$$
\begin{aligned}
& \sigma_{x y}(x=0, y=-h / 2)=\sigma_{x y}(x=l / 2, y=-h)=\frac{r^{1}}{r^{b}} \sigma_{x y}^{1} \\
& \sigma_{x y}(x=l, y=-h / 2)=\sigma_{x y}(x=l / 2, y=0)=0
\end{aligned}
$$

\subsection{Iterative coupled algorithm}

The micromechanical model of the internal structure of a damaged masonry cell has been coupled with the isotropic scalar damage model of its components, using the algorithm shown in Fig. 9. The outer loop is a cycle related to the incremental loading steps, as usual in strain driven problems, 
in which the normal cell strain parallel to the bed joint is increased. The cell boundary conditions of the problem are:

$$
\begin{aligned}
\varepsilon_{x x}^{0} & =\varepsilon_{x x}+\Delta \varepsilon_{x x} \\
\sigma_{y y}^{0} & =0 \\
\sigma_{z z}^{0} & =0
\end{aligned}
$$

The system of Eq.(55-66) has been written for a problem with imposed stresses on cell faces, which are satisfied by three stress equilibrium equations in the axis directions. In the strain driven problem defined by Eq.(71), on the contrary, the cell stress $\sigma_{x x}^{0}$ is now an unknown variable, while the cell strain $\varepsilon_{x x}^{0}$ is the known term. A governing system of equations for the new problem can then be obtained by replacing the stress equilibrium equation along the $x$ direction, Eq.(57), with the strain relation in $\mathrm{x}$ :

$$
(l+t) \varepsilon_{x x}^{0}=(l-t) \varepsilon_{x x}^{1}+2 t \varepsilon_{x x}^{3}
$$

The unknown homogenized cell stress $\sigma_{x x}^{0}$ can be obtained, after solution of the system, by means of Eq.(57). Local snap-backs have been traced using special procedures, where the crack opening or the sliding displacement serves as a control parameter. In these particular situations the system of equations is reformulated with the head joint strain or bed joint strain respectively as known increasing terms and the homogenized strain $\varepsilon_{x x}^{0}$ becomes an unknown variable of the problem. Snap-back behaviour (a phenomenon observed experimentally for quasi-brittle materials) means that the total elongation of the basic cell temporarily decreases while the material damage increases. The inner loop is an iterative process, in which at each cycle the equation system of equilibrium is solved to obtain the 
unknown effective stresses and strains, making use of the damage coefficients from the previous iteration. The damage coefficients can then be updated, by means of the damage model, from the new stresses and the process is iterated until convergence of the coefficients, within an input tolerance. Finally, the damaged internal stresses in the cell components and the unknown homogenized stress parallel to the bed joint can be derived from the values of the converged internal stresses.

\subsection{Definition of the crack opening width}

Damage models usually assume a uniform distribution of microcracks in the damaged material. Therefore, a clearly defined unique crack with a welldefined opening width does not exist. Here, opening of the head joint in a single basic cell is given by:

$$
\Delta u^{\text {head }}=2 t\left(\varepsilon_{x}^{2}-\varepsilon_{x}^{2 *}\right)
$$

where $\varepsilon_{x}^{2 *}$, see Fig. 10 , is the elastic component of the axial strain in the head joint, calculated with the elastic stiffness:

$$
\varepsilon_{x}^{2 *}=\left(1-d_{2}\right) \varepsilon_{x}^{2}
$$

Therefore, it is possible to obtain:

$$
\Delta u^{\text {head }}=2 t d_{2} \varepsilon_{x}^{2}
$$

and similarly

$$
\Delta u^{\text {bed }}=8 t d_{1} \varepsilon_{x y}^{1}
$$

It should be noted that the displacement of the head joint accounts both for the contribution of the head and bed joint fractures. Furthermore, it is stressed that the crack opening $\Delta u^{\text {crack }}$ is not $2 \Delta u^{\text {head }}$ unless we assume a perfect symmetry with the neighbouring basic cells, implying bed joint 
fracture for the entire length of a unit. Actually, if the fracture, as in Lourenço et al. (1999), localizes only on half unit (Fig. 11), the contribution to the head joint displacement due to the bed fracture will come only from one basic cell, leading therefore to:

$$
\Delta u^{\text {crack }}=2 \Delta u^{\text {head }}-\Delta u^{\text {bed }}=4 t\left(d_{2} \varepsilon_{x}^{2}-2 d_{1} \varepsilon_{x y}^{1}\right)
$$

\section{Results}

The algorithm described in the present paper has been implemented in a numerical program for the simulation of a masonry cell under normal tensile stresses. In order to check its performance, the algorithm has been tested in the fracture problem of an infinitely long wall under tensile loading parallel to the bed joint (Fig. 12), which has been analysed by Lourenco et al. (1999) with a sophisticated finite element interface model based on multisurface plasticity. This model consists of two half units in the vertical direction and of two and a half units in the horizontal direction. In the middle of the specimen a potential crack/slip line through head and bed joints is included. The unit dimensions are $900 \times 600 \times 100 \mathrm{~mm}^{3}$. With the new model, only the central basic cell in the wall is represented, but such approach does not introduce any qualitative difference with the original problem, because the relation between tensile stress and crack opening is independent from the specimen length.

The two models can be compared exactly in the case of zero dilatancy angle. In this case there is no vertical compression of the bed joint and therefore the shear strength of the mortar in the Coulomb friction model is constant and equal to the initial cohesion of the joint. The adopted material 
properties are given in Table 1 . With these data the unit will not fail, so only mortar fracture data are required. The basic expected failure mechanisms of head and bed joint are different, shear for the latter and tension for the former, so the two joints have been given different parameters in the damage model to reproduce these different behaviours. The required damage parameters $A_{t}$ and $A_{s}($ Section3.4) for the mortar can be obtained by means of Eq.(46) and (49) from the fracture energies, with the characteristic lengths $l_{t}$ and $l_{s}$ given by the head and bed joint thickness $(3 \mathrm{~mm})$, resulting in: $A_{t}=0.078, A_{s}=0.084$. Using such values, the exponential softening obtained, respectively, in tension and shear coincide with the curves:

$$
\sigma=\sigma_{t} \exp \left(-\frac{\sigma_{t}}{G^{I}} \Delta u_{t}\right) \quad, \quad \tau=\sigma_{s} \exp \left(-\frac{\sigma_{s}}{G^{I I}} \Delta u_{s}\right)
$$

The results of the proposed coupled damage-homogenisation model are shown in Fig. 13, where they are compared with the FEM analysis of Lourenco et al. (1999) in the case with zero dilatancy angle. The calculations have been performed with a convergence tolerance on the damage coefficients equal to $1 \%$. The damage model reproduces with good agreement the FEM analysis of the cell degradation and the two peaks of the failure load. The head joint is the first to fail in tension and the bed joint takes its place in the load carrying mechanism of the cell. The load is transferred through bed joint shear from unit to the other, with the cell showing regained elastic behaviour for increasing loads, until final failure of the bed joint in shear. The residual load carrying capacity is zero because there is no vertical compression, and therefore no friction effect. 
The composite fracture energy of masonry, parallel to the bed joint, can be calculated in the homogenized cell as the appropriately weighted sum of the fracture energies of bed and head joints:

$$
G=\frac{2 h G^{I}+(l-t) G^{I I}}{2(h+t)}=0.047 \mathrm{~N} / \mathrm{mm}^{2} \times \mathrm{mm}
$$

This value can be compared with the area under the stress-crack opening plots in Fig. 13. The result shows that both the damage model $\left(G \cong 0.045 \mathrm{~N} / \mathrm{mm}^{2} \times \mathrm{mm}\right)$ and the FEM analysis $\left(G \cong 0.046 \mathrm{~N} / \mathrm{mm}^{2} \times \mathrm{mm}\right)$ are very close to the expected value. The main difference is in the elastic stiffness of the cell with failed head joints, which in the damage model is about $15 \%$ higher than in the FEM analysis and reflects the same difference for the failure load of the bed joint.

\section{Conclusions}

Recently, a micro-mechanical homogenisation technique for masonry has been successfully developed, Zucchini and Lourenço (2002), by introducing new additional deformation modes in the model, resulting from the staggered alignment of the units in the composite. In this paper, an improved additional deformation mode is considered, the formulation is derived and the algorithm is applied to a non-linear problem. The problem considered is the simulation of the behaviour of a basic cell up to complete failure, under tensile loading parallel to the bed joint.

The simulation has been accomplished by coupling the elastic micromechanical model with a scalar damage model for joints and units and by means of an iterative solution procedure to calculate the damage 
coefficients. The numerical algorithm is described and tested in the fracture problem of a masonry wall under restrained shrinkage, already analysed by Lourenco et al. (1999) using a detailed FEM simulation. The comparison of the results shows the good agreement of the new homogenisation technique with the FEM solution and its capability to reproduce the main characteristics of masonry failure in tension. This is a first step in the road to produce a reliable and versatile tool for non-linear masonry simulations. 


\section{References}

CUR, 1997. Structural masonry: An experimental/numerical basis for practical design rules. Rots JG (ed). Balkema : Rotterdam.

Berto, L., Saetta, A., Scotta, R., Vitaliani, R., 2002, Orthotropic damage model for masonry structures. International Journal for Numerical Methods in Engineering, 55(2), 127-157.

Dhanasekar, M., Page, A.W., Kleeman, P.W., 1985, The failure of brick masonry under biaxial stresses. Proc. Intsn. Civ. Engrs., Part 2., 79, $295-313$.

Lopez, J., Oller, S., Oñate, E., Lubliner, J., 1999. A homogeneous constitutive model for masonry, International Journal for Numerical Methods in Engineering 46, 1651-1671.

Lourenço, P.B., 1998. Experimental and numerical issues in the modeling of the mechanical behavior of masonry. In: Roca P \& al. (ed) Structural analysis of historical constructions II CIMNE : Barcelona, 57-91.

Lourenço, P.B., Rots, J.G., Blaauwendraad, J., 1998, Continuum model for masonry: Parameter estimation and validation. Journal of Structural Engineering, ASCE, 124(6), 642-652.

Lourenço, P.B., Rots, J.G., van der Pluijm, 1999. Understanding the tensile behaviour of masonry parallel to the bed joints: a numerical approach, Masonry International, 12(3), 96-103.

Maier, G., Papa, E., Nappi, A., 1991. On damage and failure of unit masonry. In: Experimental and numerical methods in earthquake engineering. Balkema, Brussels and Luxenbourg, pp. 223-245. 
Mazars, J., 1986. A model of a unilateral elastic damageable material and its application to concrete, In: Fracture Toughness and Fracture Energy of Concrete, Elsevier, New York.

Mazars, J., Pijaudier-Cabot, G., 1989. Continuum damage theory application to concrete, Journal of Engineering Mechanics, ASCE 115, 345-365.

Oliver, J., Cervera, M., Oller, S., Lubliner, J., 1990. Isotropic damage models and smeared cracked analysis of concrete, Proc. 2nd ICCAADS, vol.2, Pineridge Press, 945-958.

Pande, G.N., Liang, J.X., Middleton, J, 1989. Equivalent elastic moduli for unit masonry, Computers and Geotechnics 8, 243-265.

van der Pluijm, R., 1999. Out of plane bending of masonry: Behaviour and strength. Ph.D. Dissertation, Eindhoven University of Technology, The Netherlands.

Rots, J.G, 1991. Numerical simulation of cracking in structural masonry, Heron, 36(2), 49-63.

Scotta, R., Vitaliani, R., Saetta, R., Oñate, E., Hanganu, A., 2001. A scalar damage model with a shear retention factor for the analysis of reinforced concrete structures: theory and validation, Computers and Structures, 79, 737-755.

Zucchini, A., Lourenço, P.B., 2002. A micro-mechanical model for the homogenization of masonry, International Journal of Solids and Structures, 39, 3233-3255. 


\section{List of Figures}

Figure 1.

Modelling strategies for masonry structures: (a) detailed micro-modelling;

(b) simplified micro-modelling; (c) macro-modelling.

Figure 2.

Basic cell for masonry and homogenisation process.

Figure 3.

Definition of masonry axes and masonry components considered in the proposed approach : unit, head joint, bed joint and cross joint.

Figure 4.

Adopted geometry symbols.

Figure 5.

Original model for a cell under tensile loading along the $x$-axis.

Figure 6.

Assumed improved additional deformation mode in the unit.

Figure 7.

Comparison of the shear deformation of the model $\left(\bar{\varepsilon}_{x y}\right.$ at $\left.\mathrm{x}=0\right)$ with FEM results in a single unit problem: relative error vs. increasing unit length. 
Figure 8.

Improved model for a cell under tensile loading along the $x$-axis.

Figure 9.

Formulation of the homogenisation damage model with an iterative algorithm.

Figure 10.

Definition of the elastic component of axial strain in the head joint after failure.

Figure 11.

Definition of the crack opening width.

Figure 12.

Infinitely long masonry wall under tensile loading parallel to the bed joints.

Figure 13.

Stress/crack opening diagram for masonry under tension parallel to the bed joint : comparison between FEM results of Lourenco et al.(1999) and the coupled homogenisation-damage model. 


\section{List of Tables}

Table 1.

Elastic and inelastic properties of the masonry cell. 


\section{Table I}

\begin{tabular}{|c|c|c|c|c|c|c|}
\hline & $\begin{array}{c}\mathbf{E} \\
\left(\mathrm{N} / \mathrm{mm}^{2}\right)\end{array}$ & $\mathbf{v}$ & $\begin{array}{c}\sigma_{\mathrm{t}} \\
\left(\mathrm{N} / \mathrm{mm}^{2}\right)\end{array}$ & $\begin{array}{c}G^{I} \\
\left(\mathrm{~N} / \mathrm{mm}^{2} \times \mathrm{mm}\right)\end{array}$ & $\begin{array}{c}\sigma_{\mathrm{s}} \\
\left(\mathrm{N} / \mathrm{mm}^{2}\right)\end{array}$ & $\begin{array}{c}G^{I I} \\
\left(\mathrm{~N} / \mathrm{mm}^{2} \times \mathrm{mm}\right)\end{array}$ \\
\hline Mortar & 1000 & 0.2 & 0.50 & 0.01 & 0.75 & 0.05 \\
\hline Unit & 5000 & 0.2 & 1.3 & - & - & - \\
\hline
\end{tabular}




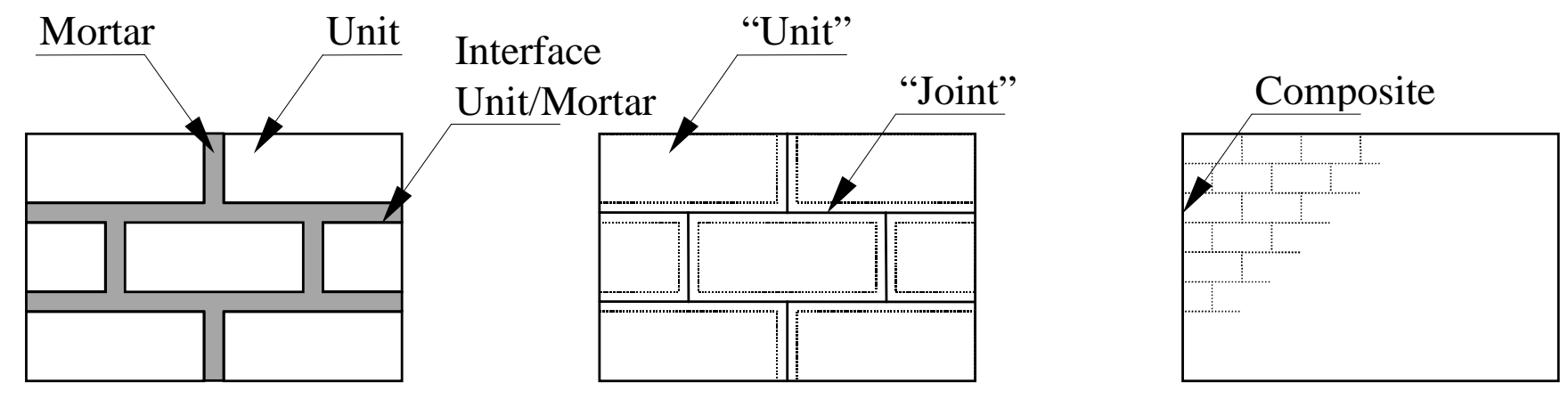

Fig. 1 


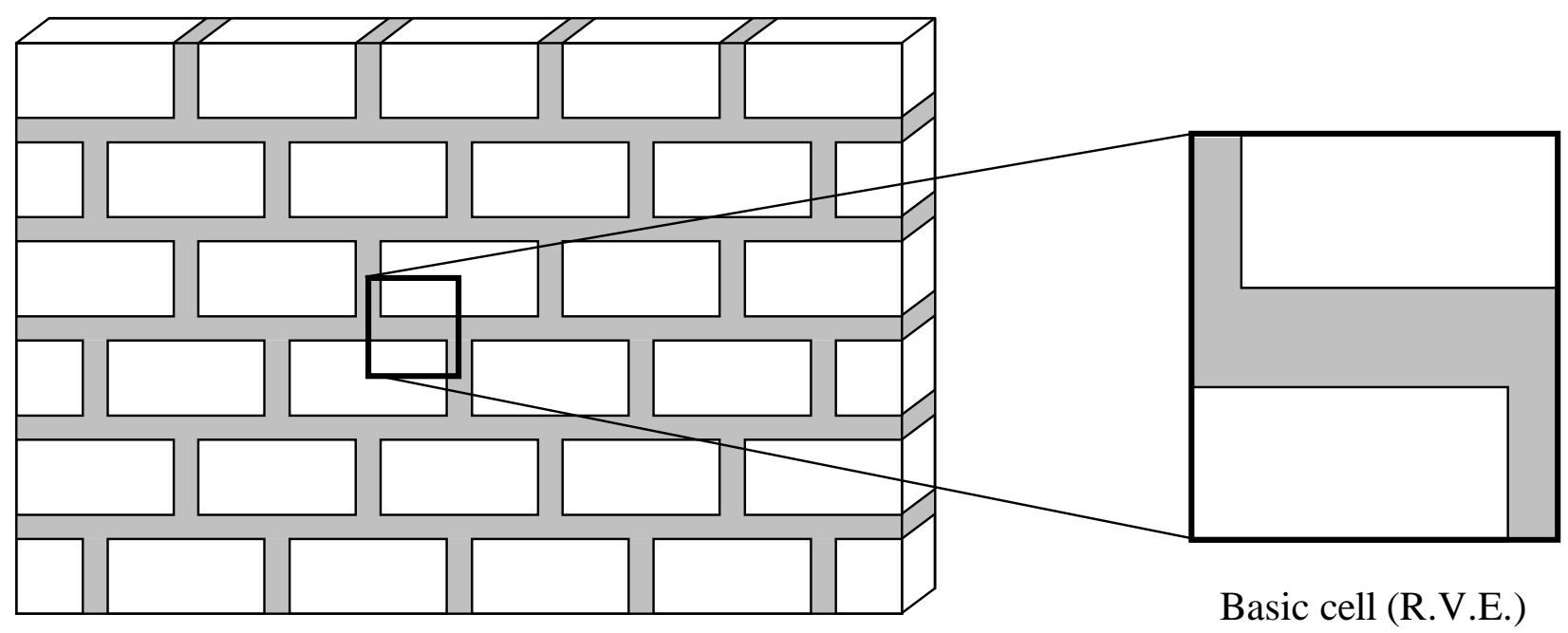

Homogenisation

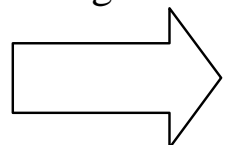

Homogenised continuum

Fig. 2 


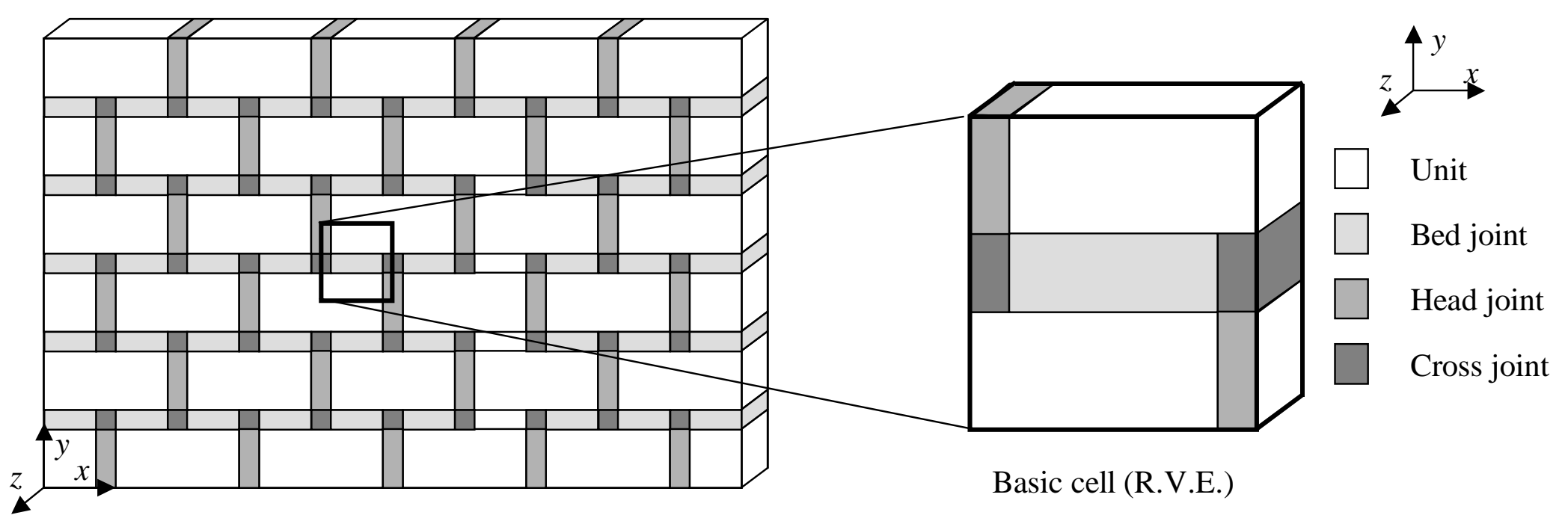

Fig. 3 


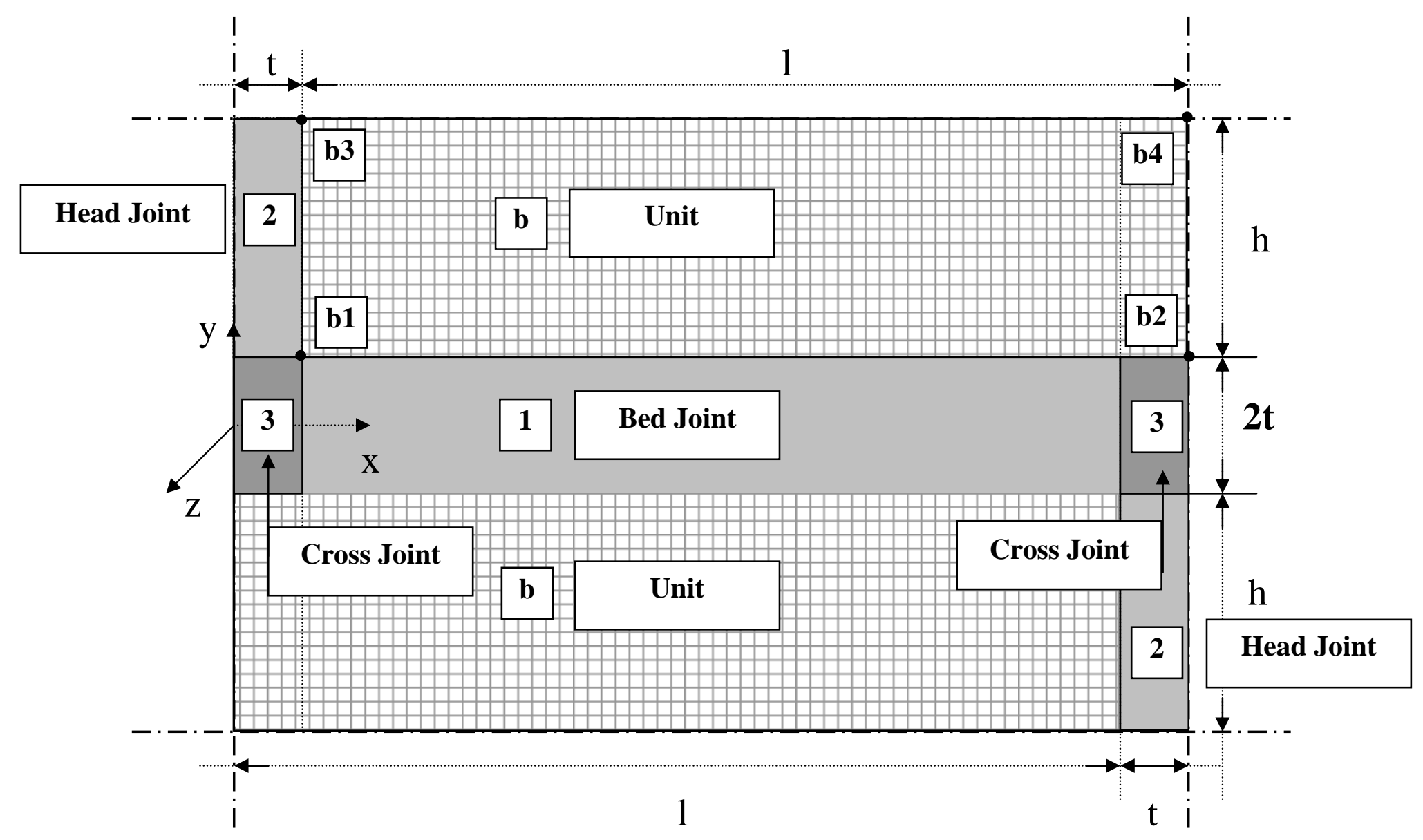

Fig. 4 


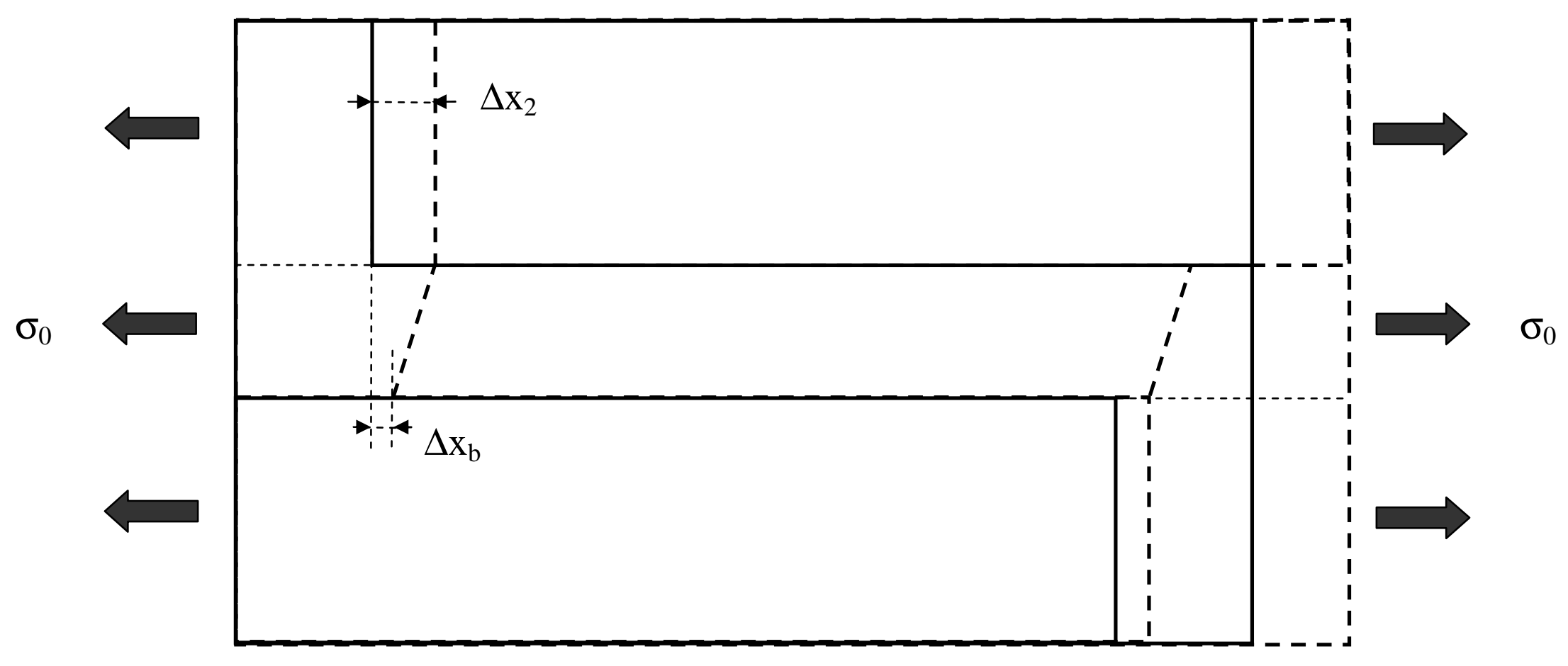

Fig. 5 


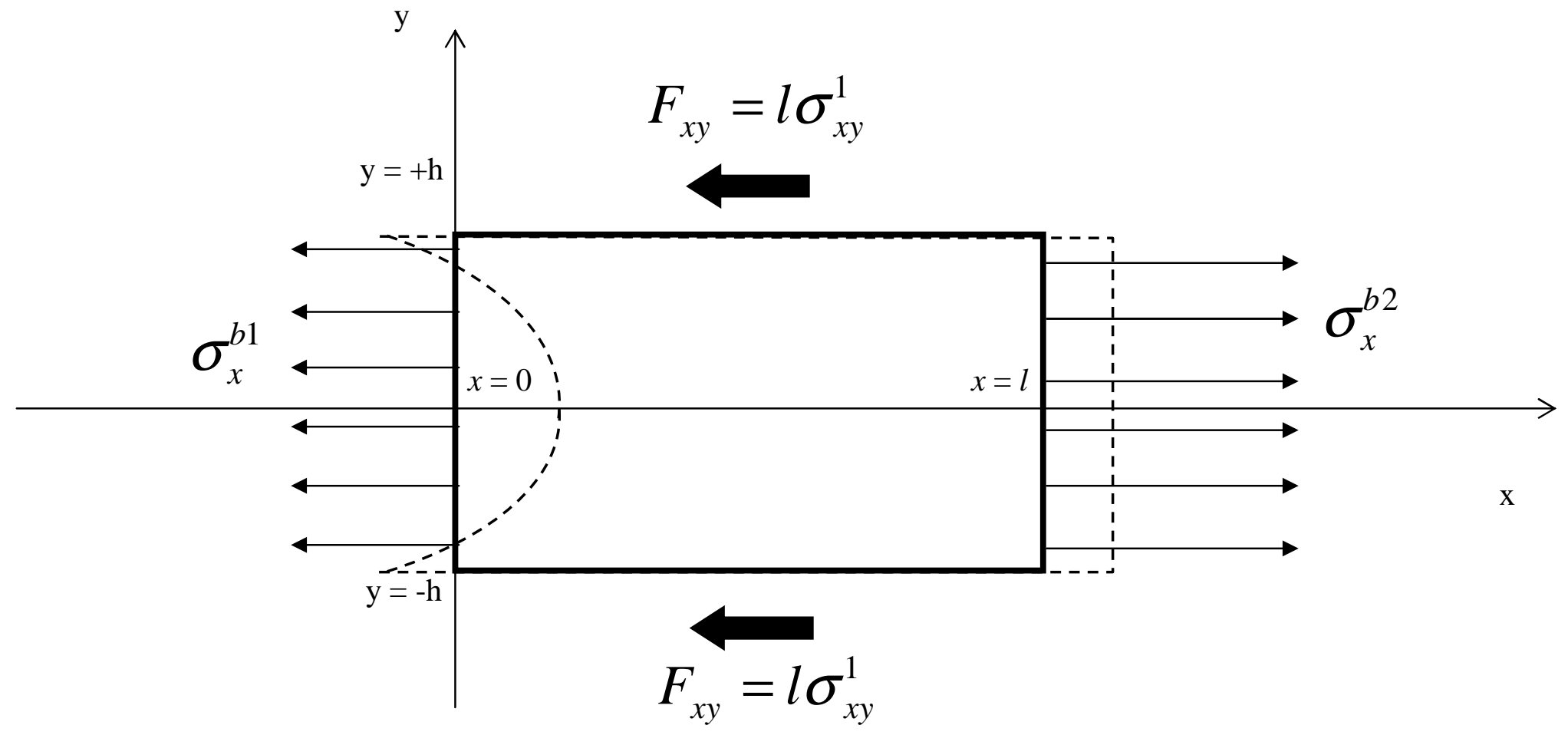

Fig. 6 


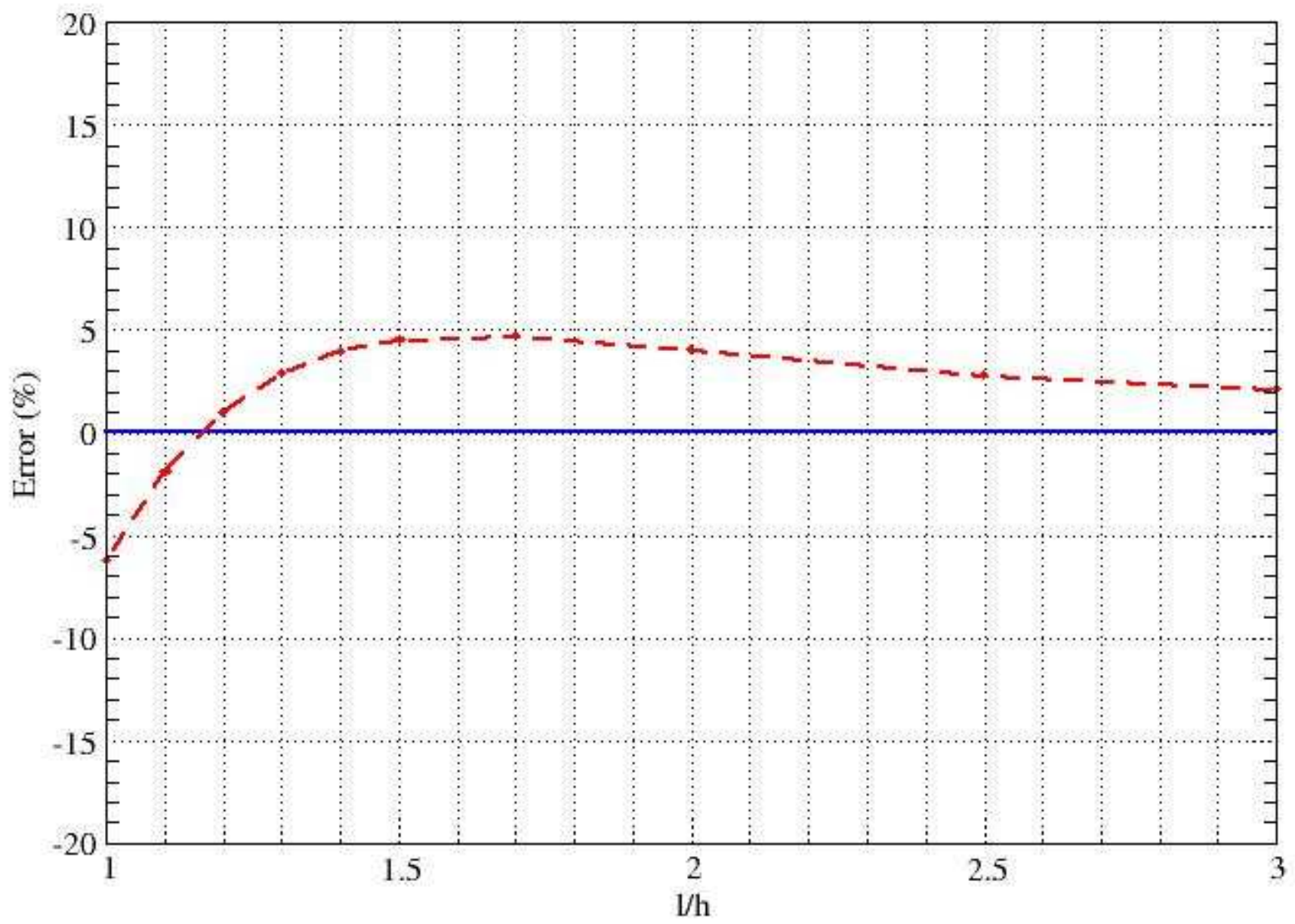

Fig. 7 


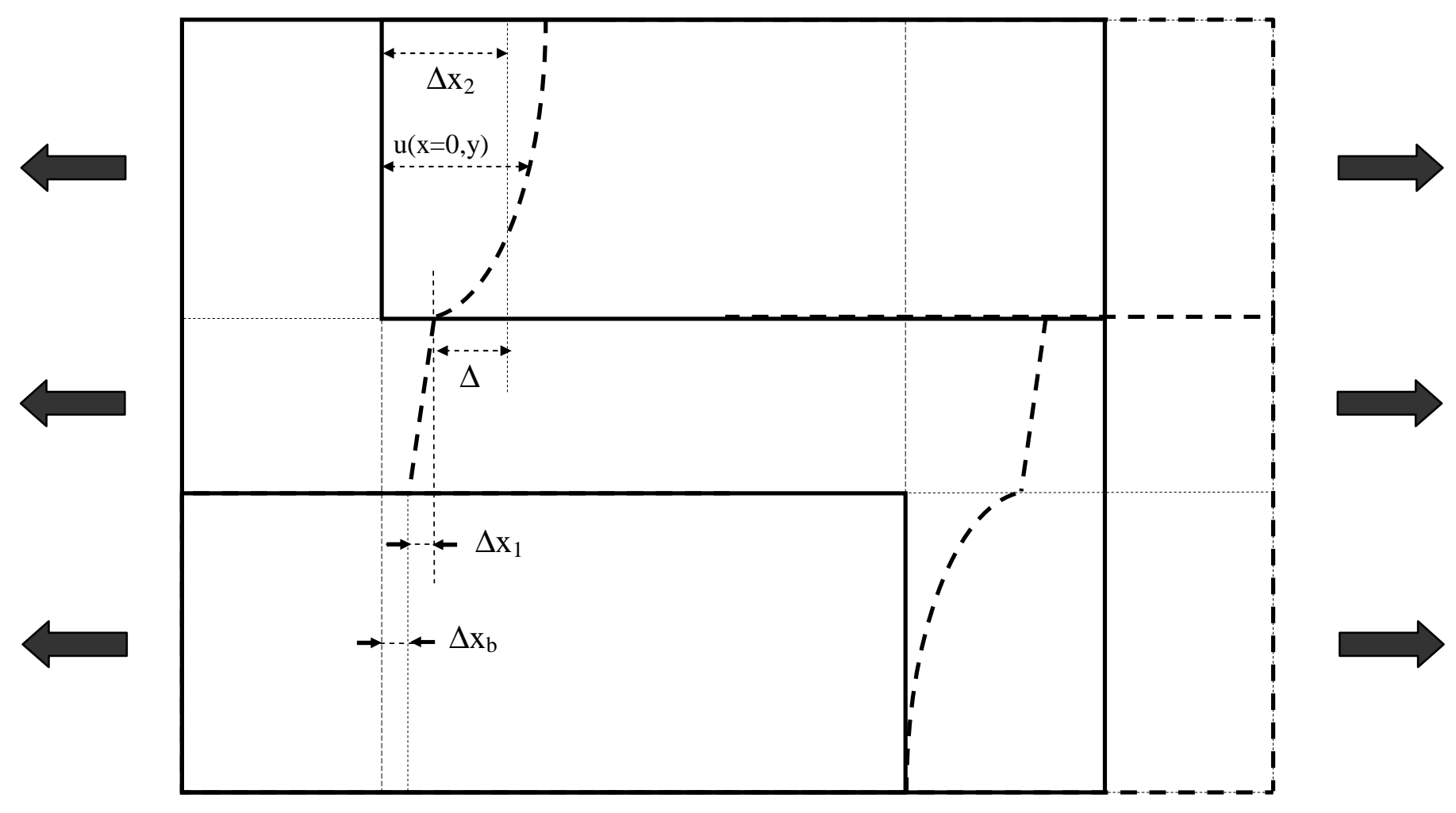

Fig. 8 


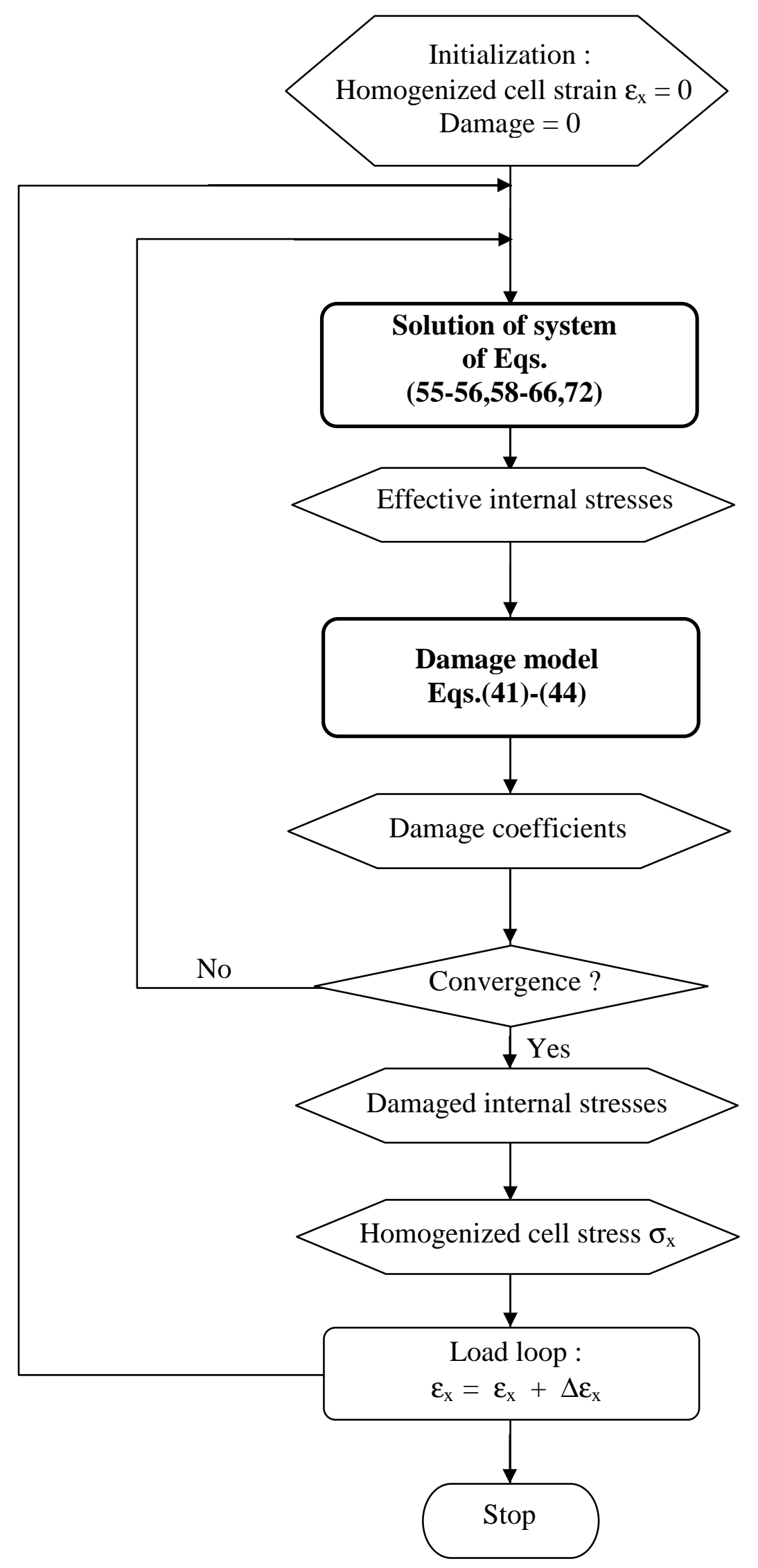

Fig. 9 


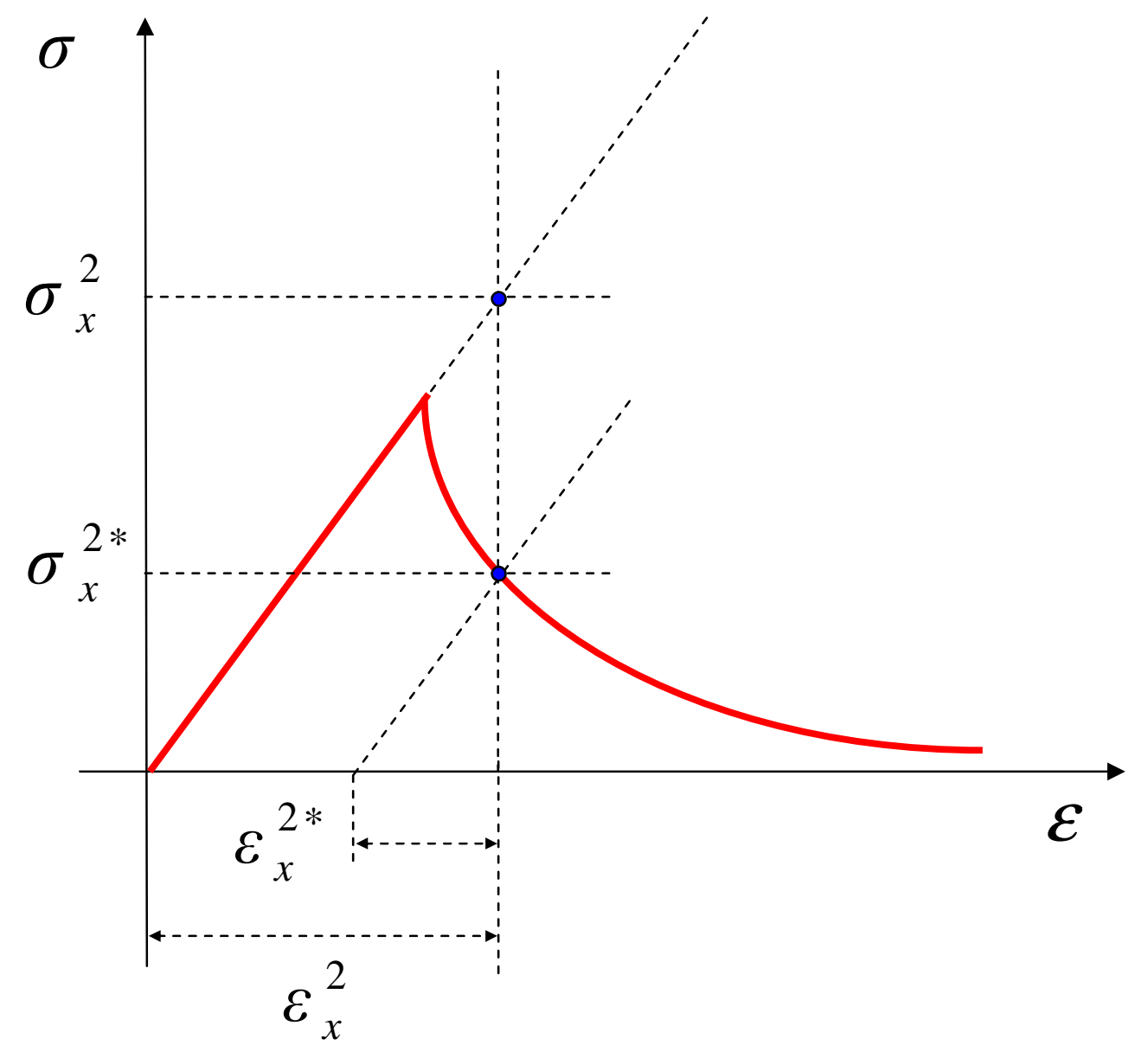

Fig. 10 


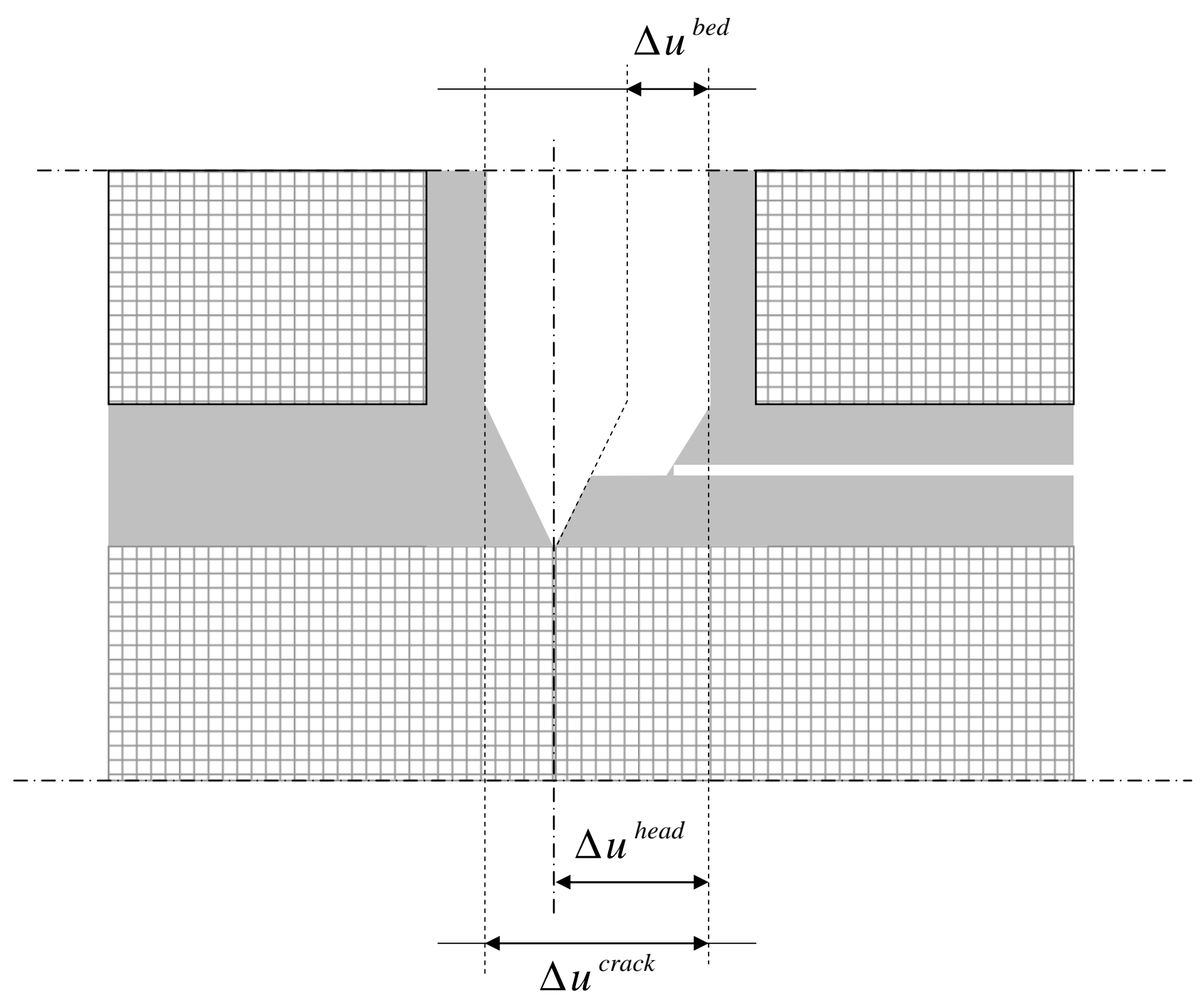

Fig. 11 


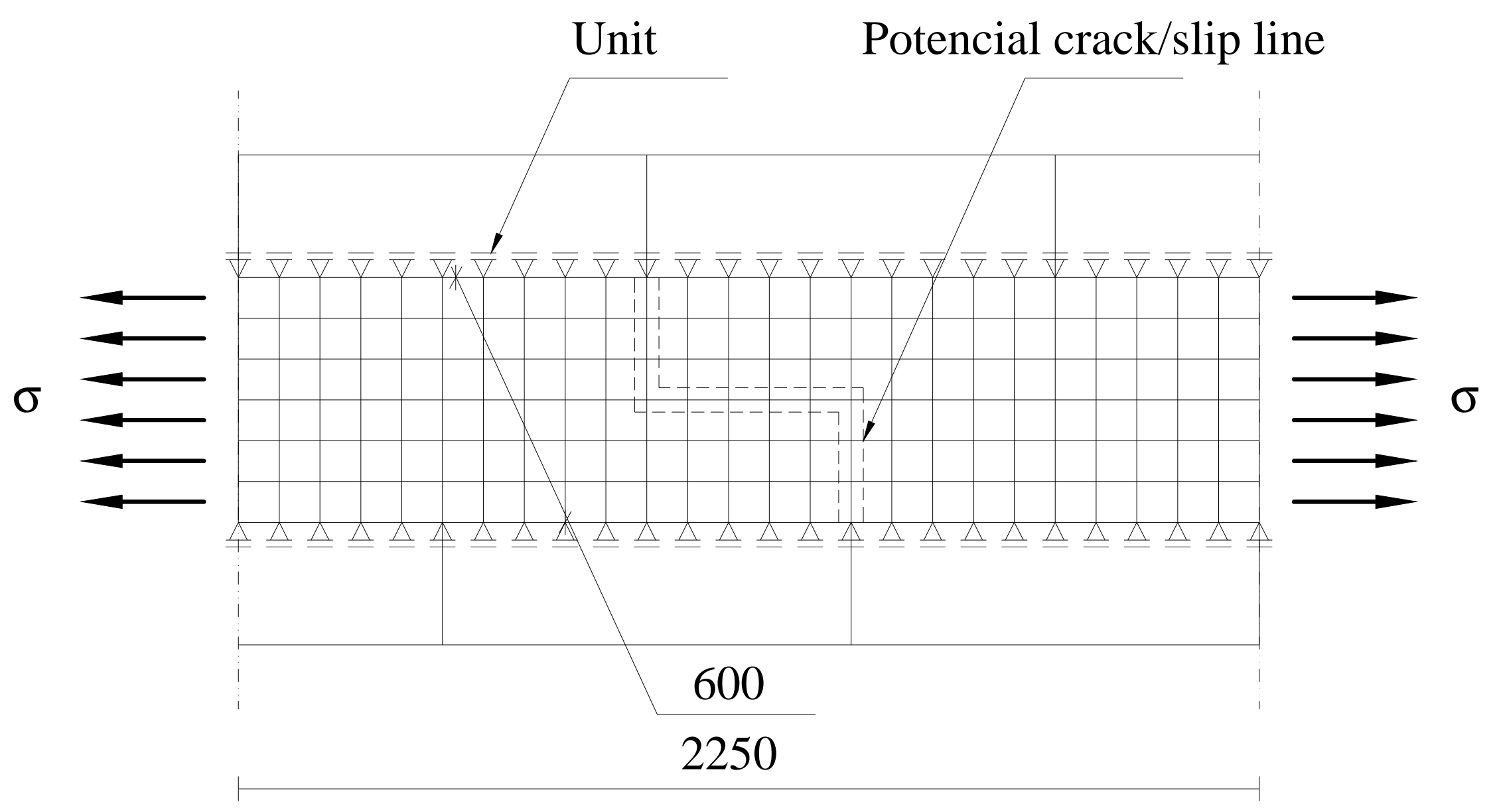

Fig. 12 


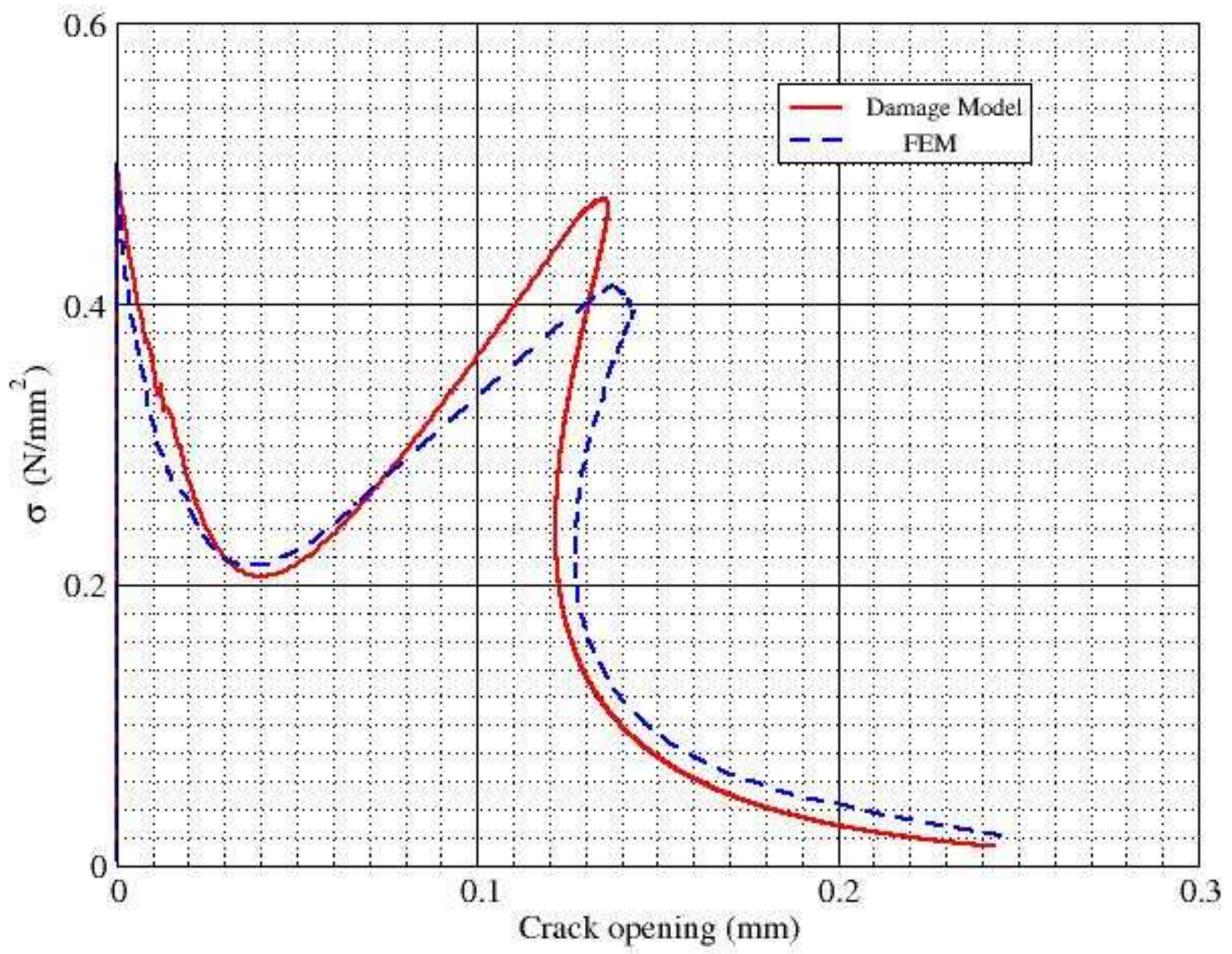

Fig. 13 